\title{
Triggered Earthquakes and the 1811-1812 New Madrid, Central United States, Earthquake Sequence
}

\author{
by Susan E. Hough
}

\begin{abstract}
The 1811-1812 New Madrid, central United States, earthquake sequence included at least three events with magnitudes estimated at well above M 7.0. I discuss evidence that the sequence also produced at least three substantial triggered events well outside the New Madrid Seismic Zone, most likely in the vicinity of Cincinnati, Ohio. The largest of these events is estimated to have a magnitude in the low to mid $M 5$ range. Events of this size are large enough to cause damage, especially in regions with low levels of preparedness. Remotely triggered earthquakes have been observed in tectonically active regions in recent years, but not previously in stable continental regions. The results of this study suggest, however, that potentially damaging triggered earthquakes may be common following large mainshocks in stable continental regions. Thus, in areas of low seismic activity such as central/ eastern North America, the hazard associated with localized source zones might be more far reaching than previously recognized. The results also provide additional evidence that intraplate crust is critically stressed, such that small stress changes are especially effective at triggering earthquakes.
\end{abstract}

\section{Introduction}

Original felt reports from the 1811-1812 New Madrid sequence have been compiled and analyzed in some detail over the years (Nuttli, 1973; Street, 1982, 1984; Johnston, 1996a, b; Johnston and Schweig, 1996; Hough et al., 2000). The sequence occurred in the so-called bootheel region of Missouri, in the southcentral United States (Fig. 1, Table 1). The town for which the sequence was named, New Madrid, was one of the earliest American settlements along the Mississippi River. A recent reanalysis of original felt reports by Hough et al. (2000) obtained $M_{\mathrm{w}}$ values of 7.0-7.5 for the three principal events on 16 December 1811, 23 January 1812, and 7 February 1812 (hereinafter, NM1, NM2, and NM3, respectively). Other studies have inferred even higher magnitude estimates for the three mainshocks (e.g., Johnston, 1996b). Although the precise magnitudes remain in question, the three principal events were clearly very large earthquakes.

All three of the principal mainshocks were felt over much of the central and eastern United States (Mitchill, 1815; Nuttli, 1973). At distances of several hundred kilometers, accounts typically describe effects consistent with substantial long-period energy; rarely do they include documentation of the effects of high-frequency shaking, such as the toppling or breaking of small objects. In this note, I discuss three events whose felt distributions are not consistent with locations within the New Madrid Seismic Zone. In some cases, their ground motions are described in terms sug- gestive of high-frequency shaking, such as smart, or as strong, but of relatively short duration. In his compilation of accounts of the New Madrid sequence, Street (1982) compiled a list of all events for which there are multiple accounts, identifying a dozen "large aftershocks" that were widely felt. In this study I focus on his accounts of the three events that seem to have been centered outside of the New Madrid region.

At the time of earlier study-1982-the seismological community did not yet generally appreciate the fact that large earthquakes are capable of triggering events at distances far greater than those associated with classic aftershocks. Since the 28 June 1992 Landers, California, mainshock, however, numerous studies have documented the reality of triggered earthquakes (Hill et al., 1992; Gomberg, 1996; Brodsky et al., 2000). Triggering appears to be associated with dynamic strain associated with the surface wave (Gomberg and Davis, 1996), although it remains unclear how the transient strains are transformed into sustained stress capable of driving a fault to failure (Brodsky et al., 2000). With an appreciation for triggered events gleaned from recent earthquakes in California and Turkey, I reexamine three of the large so-called aftershocks of the New Madrid sequence, events occurring at approximately 8:45 a.m. local time (LT) on 27 January 1812, 8:30 p.m. (LT) on 7 February 1812, and 10:40 p.m. (LT) on 7 February 1812 (hereinafter, NM2-A, NM3-A, and NM3-B, respectively). 


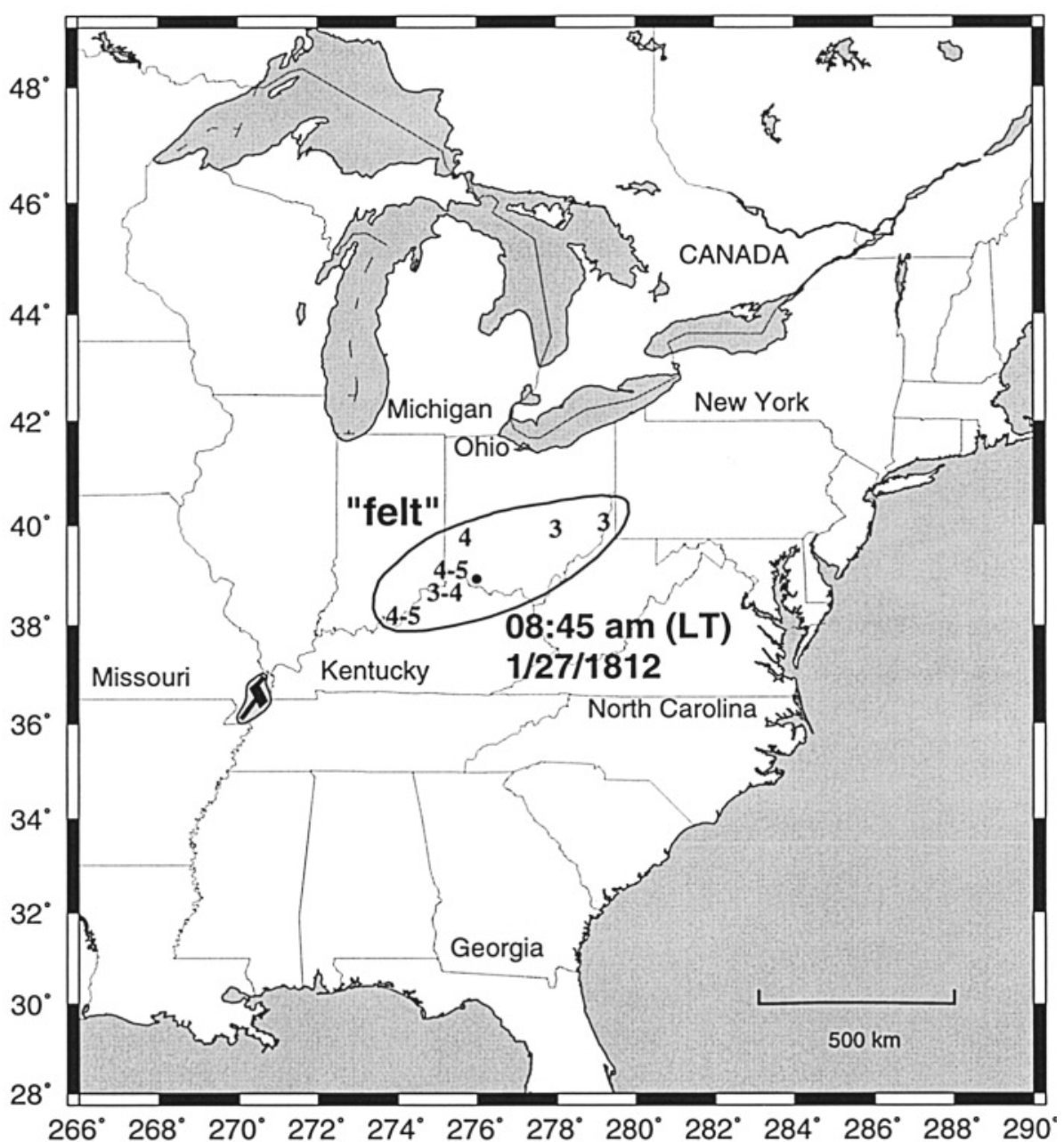

Figure 1. MMI values inferred from felt reports of event at approximately 08:45 a.m. (LT) on 27 January 1812. Symbols are centered on location of town except for the one 3-4 value, which is shifted for clarity because its true location (Newport, Kentucky) is very close to town to its immediate north (Cincinnati, Ohio). Small circle indicates plausible event location given the distribution of felt reports. Extent of faulting associated the with 1811-1812 New Madrid sequence is indicated.

Table 1

New Madrid Sequence: Mainshocks, Principal Aftershock, and Triggered Events

\begin{tabular}{lccccccc}
\hline Event & Year & Month & Day & $\begin{array}{c}\text { Local Time } \\
(\text { hr:min) }\end{array}$ & $\begin{array}{c}\text { Long.* } \\
\left({ }^{\circ}\right)\end{array}$ & $\begin{array}{c}\text { Lat.* } \\
\left({ }^{\circ}\right)\end{array}$ & $M w^{\dagger}$ \\
\hline NM1 & 1811 & 12 & 16 & $02: 15$ & -90.00 & 36.00 & $7.2-8.1$ \\
NM1-A & 1811 & 12 & 16 & $07: 15$ & -89.50 & 36.25 & $\approx 7.0$ \\
NM2 & 1812 & 1 & 23 & $08: 45$ & -89.67 & 36.58 & $7.0-7.8$ \\
NM2-A & 1812 & 1 & 27 & $09: 00$ & -84.02 & 38.94 & NE \\
NM3 & 1812 & 2 & 7 & $03: 45$ & -89.60 & 36.35 & $7.5-8.0$ \\
NM3-A & 1812 & 2 & 7 & $20: 30$ & -84.02 & 38.94 & $\approx 4.5$ \\
NM3-B & 1812 & 2 & 7 & $22: 40$ & -84.02 & 38.94 & $5.0-5.5$ \\
\hline
\end{tabular}

*Crudely estimated longitude and latitude in decimal degrees north and west.

${ }^{\dagger}$ Range of inferred moment magnitude from previous studies and this study, NE, no estimate.
The first of these events followed NM2 by approximately four days; the second and third events occurred the night following the NM3 mainshock (which occurred at approximately 3:45 a.m. LT).

\section{The 8:45 a.m. (LT) Event of 27 January 1812 (NM2-A)}

The event at approximately 8:45 a.m. (LT) on 27 January 1812 (NM2-A) is among the so-called aftershocks described as having been felt throughout the midwest (Street, 1982). The locations of the accounts of this event are shown in Figure 1 and listed in Table 2. In all of these locations, NM2 is also described as having been felt, and so there is no possibility that the two dates have simply been confused.

In many of the locations, shaking from NM2-A is described as having been "violent," "severe," or "smart." From 
Table 2

8:45 a.m. (LT) 27 January 1812 Event (NM2-A)

\begin{tabular}{lccccc}
\hline Location & Long. & Lat. & MMI & Report* & Source $^{\dagger}$ \\
\hline Cincinnati, Ohio & -84.54 & 39.14 & $4-5$ & "second class in severity" & D1815 \\
Dayton, Ohio & -84.20 & 39.78 & 4 & considerable agitation & S1984 \\
Louisville, Kentucky & -85.74 & 38.22 & $4-5$ & "violent," second class in severity & F1912 \\
Newport, Kentucky & -84.49 & 39.09 & $3-4$ & "smart shock" & S1984 \\
Wheeling, West Virginia & -80.70 & 40.08 & 3 & "slight shock" & S1984 \\
Zanesville, Ohio & -82.01 & 39.95 & 3 & "slight shock" & S1984 \\
\hline
\end{tabular}

* Summary of firsthand reports on which MMI values are based.

†Source of information: D1815, Drake, (1815); S1984, Street (1984); F1912, Fuller, (1912).

these accounts, modified Mercalli intensity values can be estimated (Table 2, Fig. 1). The most noteworthy feature of the accounts of event NM2-A is that none exist within 200 $\mathrm{km}$ of the New Madrid region. Rather, all of the available accounts are from the Ohio/northern Kentucky region. Although it is possible that Street's 1982 compilation is simply missing accounts of this event from the New Madrid region, both the spatial distribution of accounts and the types of motion described strongly suggest an earthquake source near the observers.

One resident of Cincinnati, Ohio, Daniel Drake, kept a careful record of the New Madrid sequence, which corroborates the evidence for a location near Cincinnati (Drake, 1815). Drake devised a scale to rank the events by severity of shaking, assigning the three principal mainshocks to what he termed the "first class" on his scale. He further identified four other events as occupying a "second class": 7:20 a.m. (LT) on 16 December 1811 (hereinafter, NM1-A), 8:45 a.m. (LT) on 27 January 1812 (NM2-A) (Fig. 1), 8:30 p.m. (LT) on 8 February 1812 (NM3-A) (Fig. 2), and 10:40 p.m. (LT) on 8 February 1812 (NM3-B) (Fig. 3). The first of these events, NM1-A is almost certainly the large aftershock known to have struck the New Madrid region the morning following the first mainshock. The NM1-A event was widely felt over much of the United States, and it caused significant damage in the New Madrid region (Mitchill, 1815; Johnston and Schweig, 1996). As shown in Figure 1, however, the NM2-A event is not described in accounts from the New Madrid region, even though some of these accounts, such as that by New Madrid resident Eliza Bryan and accounts in the Louisville Gazette, span the entire sequence (see Street, 1982). The question of completeness of the historic record remains and will be addressed in the Discussion.

\section{The 8:30 p.m. and 10:40 p.m. (LT) Events of 7 February 1812 (NM3-A and NM3-B)}

At a number of locations throughout the midwest, accounts describe two especially strong events on the night of the NM3 mainshock, at approximately 8:30 p.m. and 10:40 p.m. (LT) (Fig. 2, 3, Tables 3, 4). In all of these locations, the 3:45 a.m. (LT) mainshock of 7 February 1812 is clearly described as well, so, once again, there is no chance that the events have been confused. As is the case for NM2-A, many of the accounts describe the shaking from NM3-B as "severe" or "violent." The NM3-A event is generally described as less severe than NM3-B, but still strong.

In Figure 3 and Table 3, I include an account by Daniel Drake among those for event NM3-B. Drake's account begins as follows, "At 40 minutes past 10 o'clock a shock considerably stronger than either of the preceding." It is unclear from this sentence which preceding events Drake is referring to, but his later account makes it clear that both NM3-A and NM3-B were smaller than NM3. Drake's account continues:

At 40 minutes past 10 o'clock a shock considerably stronger than either of the preceding. It was observed to produce in suspended and elevated bodies a very sensible degree of trembling, but no oscillation; indicating, perhaps, a vertical instead of the horizontal motion of the previous shocks. Immediately before this shock I had the satisfaction of hearing, for the first time, a noise such as preceded, according to the report of some of our citizens, most of the principal earthquakes. It was a peculiar, faint, dull, rumbling or rushing sound, near the horizon, to the southwest. It seemed to approach but not arrive at the place of observation, and after continuing four or five seconds was succeeded by the shake. (p. 235).

In Drake's original account, this event is described as having been at 10:40 p.m. (LT) on 8 February 1812 (Drake, 1815). However, later in his account, Drake discusses the weather conditions throughout the sequence: "The morning of the 7th, after the great earthquake, was calm; in the afternoon the wind, attended with snow, recommenced, and continued through the night. At the time of the shocks of that night, which were of the second class, it was snowing copiously" (pp. 241-242).

Although an often-cited 1912 publication on the New Madrid sequence gives the date of the previously mentioned event as 8 February 1812 (Fuller, 1912), the aforementioned account seems to indicate clearly that the event occurred on the same day as NM3. This conclusion derives an additional measure of support from the absence of accounts of a strong 


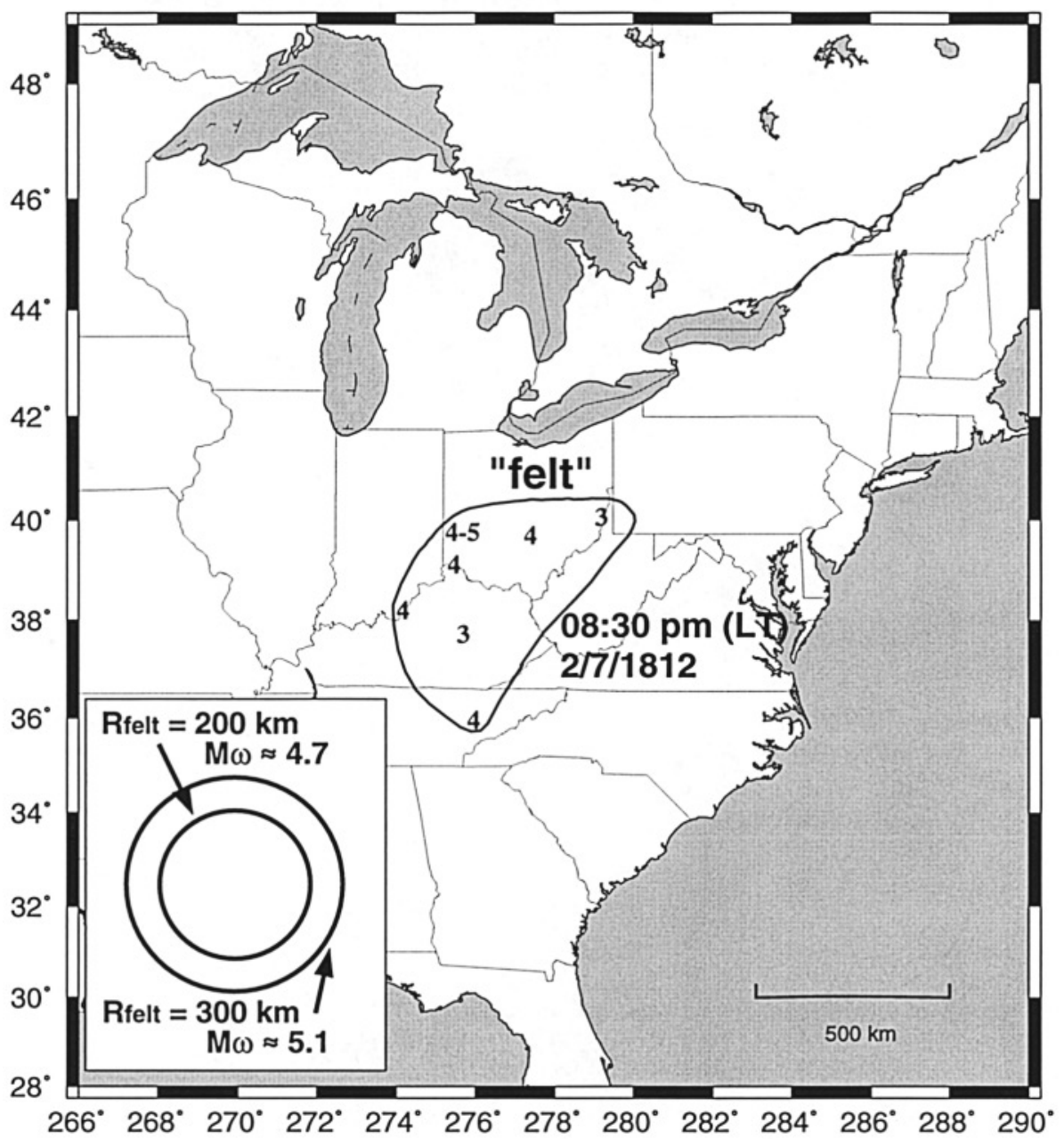

Figure 2. Same as Figure 1, but for 8:30 p.m. (LT) event of 7 February 1812. Small circle indicates plausible event location given the distribution of felt reports. Inset shows circular felt areas that correspond to $M_{\mathrm{w}}$ values of 4.7 and 5.1 given established regressions between isoseismal areas and magnitude.

event on the night of 8 February 1812 from other locations. With two different dates given by Drake for the same event, the obvious inference is that the correct date is the one that is consistent with accounts from other locations.

In light of the overall distribution of accounts of NM3B, Drake's account is suggestive of a moderate, local event in several respects. First, the account suggests that in Cincinnati, shaking from the NM3-B event were comparable to those that Drake described from the 7:20 a.m. (LT) aftershock of 16 December 1811. If the NM3-B event had been in the New Madrid region, one would expect to find accounts of shaking in that area comparable to those for the December aftershock. Drake also describes the event as having been audible, unlike any of the others (in his personal experience). This perhaps suggests that the ground motions may have had more high-frequency energy (above $20-30 \mathrm{~Hz}$, the threshold of audible sound for humans) than the principal New Madrid events had generated at that location. Because seismic energy at audible frequencies attenuates rapidly with distance, this suggests a relatively local event. Drake describes the time lag between rumbling and shaking of $4-5 \mathrm{sec}$. It is possible that he heard rather than felt the $P$ wave and that the initial shaking corresponded to the $S$ wave. In this case, a distance of 32-40 km from Cincinnati would be inferred. Finally, the described lack of "oscillation" is also suggestive of a local, moderate event rather than a distant, larger one, since the former would generate far less long-period energy, but relatively more high-frequency shaking ("trembling").

Daniel Drake was one of two individuals who endeavored not only to document every event they felt, but also to rank the events by severity of shaking. The other individual was Jared Brooks, of Louisville, Kentucky (see Casseday, 1852; Fuller, 1912). Brooks describes NM3-A as having been, "violent in the first degree, but of too short duration to do much injury." (He presumably means short in relation to the shaking from the New Madrid mainshocks, which are typically described as lasting for 2-4 min in the OhioKentucky region.) Echoing Drake, Brooks describes the 


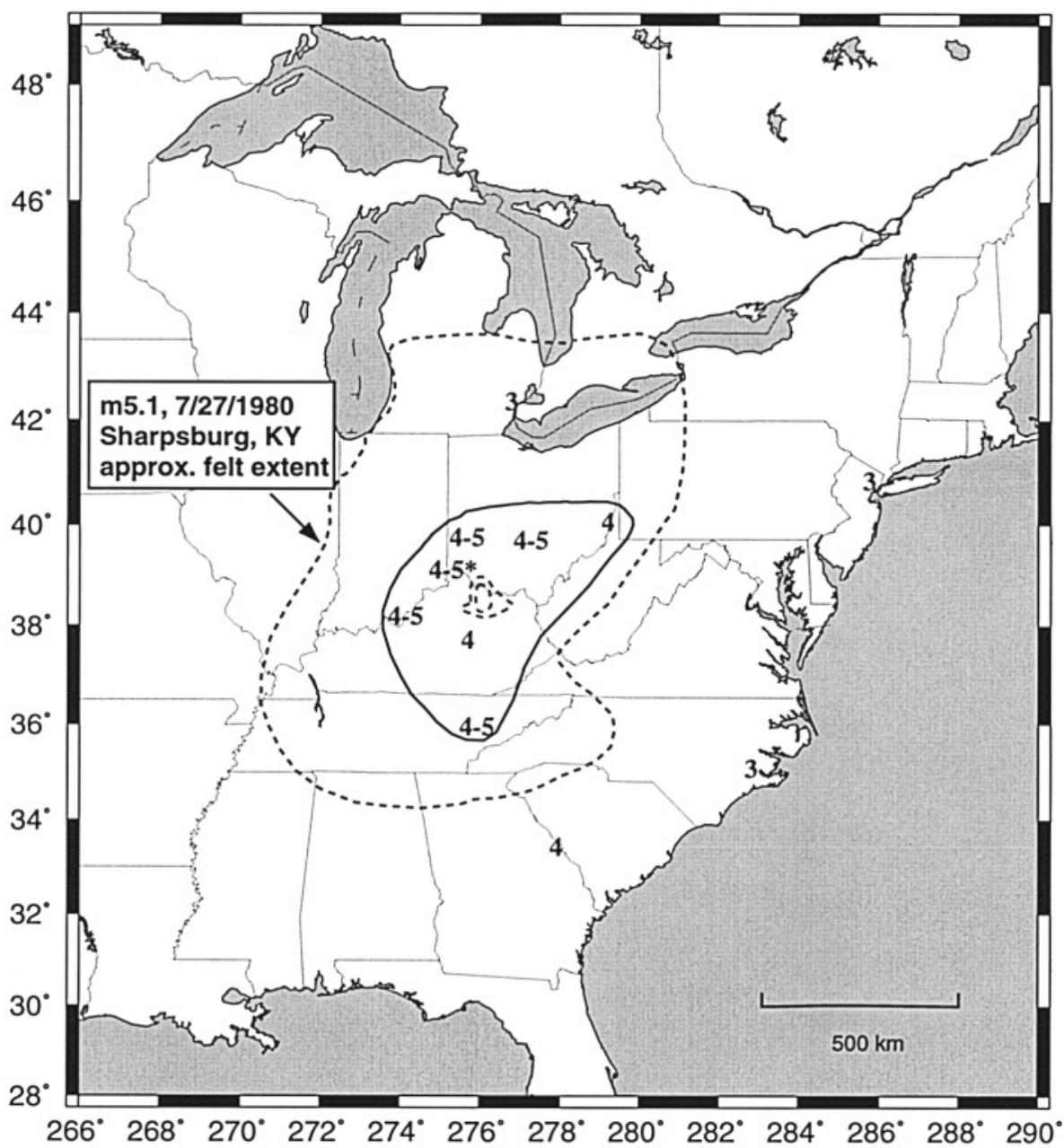

Figure 3. Same as Figure 1, but for 10:40 p.m. (LT) event of 7 February 1812. The asterisk indicates the account of Daniel Drake for Cincinnati, Ohio (see text). All symbols are centered on town location, except for New York City, which is shifted slightly west for clarity. The dashed lines indicate isoseismal contours from the $m_{\mathrm{b}} 5.1$ 1980 Sharsburg, Kentucky earthquake. The two inner lines indicate the contours for MMI V and VI, and the outer contour indicates the felt extent of the event. Note that event NM3-B was felt at three locations well outside this area.

Table 3

8:30 p.m. (LT) 7 February 1812 Event (NM3-A)

\begin{tabular}{lccccc}
\hline Location & Long. & Lat. & MMI & Report* & Source $^{\dagger}$ \\
\hline Cincinnati, Ohio & -84.54 & 39.14 & 4 & "vibration lasting 1 min." & F1912 \\
Dayton, Ohio & -84.00 & 39.78 & $4-5$ & "severe" & S1984 \\
Knoxville, Tennessee & -83.95 & 35.97 & 4 & "furniture agitated" & S1984 \\
Lancaster, Ohio & -82.60 & 39.72 & 4 & "considerable shake" & S1984 \\
Louisville, Kentucky & -85.74 & 38.22 & 4 & violent, too short to cause injury & F1912 \\
Richmond, Kentucky & -84.29 & 37.74 & 3 & felt & S1984 \\
Wheeling, West Virginia & -80.70 & 40.08 & 3 & slight shock & S1984 \\
\hline
\end{tabular}

*Summary of firsthand reports on which MMI values are based.

${ }^{\dagger}$ Source of information: S1982, Street, (1982); F1912, Fuller, (1912). 
Table 4

10:40 p.m. (LT) 7 February 1812 Event (NM3-B)

\begin{tabular}{lccccc}
\hline Location & Long. & Lat. & MMI & Report* & Source $^{\dagger}$ \\
\hline Augusta, Georgia & -82.00 & 33.46 & 4 & "smart" & S1984 \\
Cincinnati, Ohio & -84.54 & 39.14 & $4-5$ & "very sensible trembling" & D1815 \\
Dayton, Ohio & -84.20 & 39.78 & $4-5$ & "severe shock" & S1984 \\
Detroit, Michigan & -83.01 & 42.38 & 3 & "small shock" & F1912 \\
Knoxville, Tennessee & -83.95 & 35.97 & $4-5$ & "considerable violence" & S1984 \\
Lancaster, Ohio & -82.60 & 39.72 & $4-5$ & "severe, less terrible than NM3" & S1984 \\
Louisville, Kentucky & -85.74 & 38.22 & $4-5$ & violent-tremendous & F1912 \\
New Bern, North Carolina & -77.08 & 35.12 & 3 & nearly equal to NM3 & S1984 \\
New York, New York & -73.94 & 40.67 & 3 & felt by a few & S1984 \\
Richmond, Kentucky & -84.29 & 37.74 & 4 & most violent since NM3 & S1984 \\
Wheeling, West Virginia & -80.70 & 40.08 & 4 & children wakened & S1984 \\
\hline
\end{tabular}

*Summary of firsthand reports on which MMI values are based.

†Source of information: D1815, Dranke, (1815); S1984, Street (1984); F1912, Fuller, (1912).

shaking from NM3-B as "violent in the second degree," quickly strengthening to "tremendous," which is the descriptor Brooks reserved for the most severe levels of shaking (Casseday, 1852). According to Brooks, the strongest shaking from NM3-B lasted only a few seconds, again suggestive of an event in the midwest rather than the New Madrid region.

\section{Discussion}

Any analysis of historic accounts will be plagued by questions of completeness. In this case, one cannot be absolutely sure that the events discussed here-NM2-A, NM3A, and NM3-B-were not large New Madrid aftershocks that were simply not documented by anyone in the New Madrid region. However, I suggest that it is implausible that not one, but three separate large aftershocks would have gone undocumented. Moreover, I conclude that several lines of evidence point to locations well outside the New Madrid Seismic Zone. The accounts consistently describe NM3-B as the largest of the three events. Whether or not one accepts the conclusion regarding which of Drake's two dates is correct for this event, the distribution of accounts provides a fairly compelling argument for a location in southwestern Ohio or northern Kentucky. A similar location is suggested for the NM2-A and NM3-A events. Additionally, Drake documents another small handful of events with ground motions described as "short but strong" in Cincinnati: on 17 and 21 February 1812 and on 5 March 1812 (Drake, 1815). Such accounts are consistent with smaller local events.

The interpretation of a source near Cincinnati hinges on one's interpretation of Drake's account of NM3-B, which is obviously open to question. I note that the overall distribution of intensities for this event is fairly consistent with that observed for the $m_{b} 5.1$ Sharpsburg, Kentucky, earthquake of 1980 (Mauk et al., 1982). This event occurred approximately $90 \mathrm{~km}$ SE of Cincinnati. Its felt area extended to a longitude of approximately $80^{\circ} \mathrm{W}$ (Fig. 3); it was not felt along the Atlantic coast or in central Georgia, as was NM3-B.

Considering the sparse felt report distribution available for NM2-A, NM3-A, and NM3-B, I do not consider a detailed interpretation of isoseismal areas to be justified. However, one can perhaps obtain crude estimates of the shaking distribution for NM3-B. Accounts that describe ground motions as "violent" or "severe" but do not document damage are generally consistent with MMI values of IV-V (see Hough et al., 2000). As an estimate, the radius of the such shaking appears to have been on the order of $300 \mathrm{~km}$ for NM3-B. Using the regression results developed by Johnston (1996a) for eastern North America and assuming MMI values of $\mathrm{V}$ for the "violent/severe" accounts, one obtains a $M_{\mathrm{w}}$ value of 5.9. If one instead assumes that the accounts of "violent/severe" shaking correspond to MMI values of IV, one obtains $M_{\mathrm{w}} 5.3$.

Allowing for the possibility that some of the sites may have experienced amplification due to local site conditions and that the MMI IV-V area was not circular as assumed, I suggest that the accounts of NM3-B are consistent with a magnitude in the low to mid $M 5$ range. If anything, the extent of the felt radius implies an even higher magnitude, but a magnitude of $M$ 5.5-6.0 appears improbable given the lack of reported damage in Cincinnati and elsewhere. That is, according to the diary of preacher Daniel Banks, by 1815 Cincinnati had a population of approximately 4500 , with 350 houses, most of which were brick (Banks, 1815). And using the ground-motion relations of Atkinson and Boore (1995), a $M$ 5.5-6 event at 50-km distance would generate peak accelerations of approximately $10 \% \mathrm{~g}$, a level of shaking that is expected to damage masonry structures. However, the event could have been this large (or larger) if its location was farther from Cincinnati.

As an even more crude (and conservative) estimate, events NM2-A and NM3-A appear to have been felt out to a radius of at least $300 \mathrm{~km}$. Assuming this to correspond to the MMI III isoseismal, one obtains $M_{\mathrm{w}} 5.0$ for both events. 
However, with fewer accounts, these estimates are both more uncertain and more likely to be biased by site response.

Considering the extent of its felt area, event NM3-B appears to have been a substantial event. An event of $M_{\mathrm{w}}$ $\geq 5$ would be among the largest to have occurred in the southern Ohio-northern Kentucky region in historic times (Seeber and Armbruster, 1991; Frankel et al., 1996). Given the established rate of background seismicity in the entire central-eastern United States, $M_{\mathrm{w}} \geq 5$ events are expected to occur only once every 10-100 yr (Frankel et al., 1996). $M_{\mathrm{w}}$ $\geq 4$ events are expected only about once a year, on average. The odds of experiencing a $M_{\mathrm{w}} \geq 5$ event (anywhere in the central-eastern United States) by random chance in any given week are over 1 in 500 . The odds that substantial $\left(M_{\mathrm{w}}\right.$ $\geq 4$ ) events would occur (by chance) shortly after both NM2 and NM3 are lower still.

It is perhaps no surprise that the New Madrid mainshocks would have produced triggered earthquakes at regional distances. A number of recent studies have documented remotely triggered earthquakes following mainshocks of $M_{\mathrm{w}} \approx 7$ and greater, including the 1992 Landers, California, and 1999 Izmit, Turkey events (Hill et al., 1992; Bodin and Gomberg, 1994; Gomberg and Davis, 1996; Brodsky et al., 2000). These events appear to be triggered by the dynamic stress change associated with the surface waves, as the static stress changes at such large distances is very small (e.g., Gomberg and Davis, 1996). However, all previously documented cases are in regions with high rates of tectonic activity clearly associated with plate-boundary processes. The observation that small stress changes trigger earthquakes has been interpreted as implying that triggered events are those that were on the brink of failure at the time of the triggering.

Although uncertainty remains regarding the magnitudes of the principal New Madrid events, the evidence argues that the February mainshock in particular had a magnitude well above $M_{\mathrm{w}} 7.0$ (Nuttli, 1973; Street, 1982; Johnston, 1996b; Hough et al., 2000). Strains of $10^{-5}-10^{-6}$ (at frequencies of $0.1-0.5 \mathrm{~Hz}$ ) have been shown to be sufficient to trigger earthquakes at regional $(500-1000 \mathrm{~km})$ distances; it has also been shown that earthquakes of $M_{\mathrm{w}} 7.0-7.3$ will produce dynamic strains in this range at distances of $500-1000 \mathrm{~km}$ (Gomberg and Davis, 1996). Moreover, it is quite possible that triggering is a function of shaking duration, as has been argued for triggered volcanic eruptions (Brodsky et al., 1998), and the New Madrid mainshocks appear to have generated prolonged $L g$ wave trains at regional distances.

It thus appears that ground motions from the New Madrid mainshocks would have been sufficient to trigger earthquakes throughout most of Ohio. Although previous studies have documented the tendency for triggered events to occur preferentially in volcanic/geothermal regions (Hill et al., 1992; Gomberg and Davis, 1996), this study supports the conclusion that triggered events do occur in other tectonic environments as well (Bodin and Gomberg, 1994; Brodsky et al., 2000). As recently summarized by Townend and Zo- back (2000), intraplate crust appears to be closer to a critically stressed state-pervasively closer to failure-than crust in interplate regions. In such an environment, even a small dynamic stress change associated with surface waves could represent a substantial increment relative to the slow background rate of strain accumulation.

Intraplate triggering (as a common phenomenon following large mainshocks) is also consistent with the prevalence of unnaturally triggered ("induced") seismicity in such areas (Seeber, 2000). Perhaps naturally triggered earthquakes should be expected following large mainshocks in stable continent regions (SCR), even more so than in active areas, but haven't been observed simply because the rate of $M_{\mathrm{w}}$ $\geq 7$ mainshocks is so low. To date, remotely triggered earthquakes have not been documented for the $M_{\mathrm{w}} 7.7 \mathrm{Bhuj}$, India, earthquake of 26 January 2001 (Bendick et al., 2001). However, a $M 4$ event did occur in a relatively aseismic part of southern India the day following the mainshock.

The occurrence of remotely triggered earthquakes during the New Madrid sequence raises an intriguing possibility that substantial triggered events might have occurred immediately following the passage of the large-amplitude surface waves. Such near-immediate triggering has been commonly observed in California (e.g., Hill et al., 1992; Hough and Kanamori, 2001). Following the 16 October 1999 Hector Mine, California, earthquake, an early triggered event near the Salton Sea generated local peak acceleration of approximately $10 \% g$. Hough and Kanamori (2001) estimated a $M 4.6$ for this event. We further note that the location of the inferred New Madrid remotely triggered events corresponds to an area of locally high intensities for the New Madrid mainshocks. As a speculation, we suggest locally triggered earthquakes may in some cases control the intensities inferred for historic mainshocks and that it might be fruitful to look for evidence of remotely triggered earthquakes in regions where mainshock intensities are anomalously high.

The occurrence of triggered earthquakes in a SCR setting suggests that abundant crustal (geothermal/volcanic) fluids facilitate triggering but are not required for triggering to occur. One plausible mechanism, then, is a stress corrosion model in which subcritical crack growth is accelerated by the dynamic strains associated with the surface waves (Brodsky et al., 2000). One remaining question, however, is why such a process would produce triggered earthquakes after a delay of a few hours to a few days. As a speculation, I suggest that perhaps the earliest triggered events do occur almost immediately, as has been seen in cases where data exist to address the issue (e.g., Hill et al., 1992; Hough and Kanamori, 2001) and that, following the passage of the surface wave, the subsequent triggered events form their own, local sequence. That is, perhaps early triggered events can be regarded as foreshocks that sometimes lead to subsequent remote mainshocks. Indeed, substantive triggered events appear to happen within the same time frame as mainshocks following foreshocks - a few hours to a few days. Of course, 
this hypothesis does not fully answer the question of what the triggering process is; rather, it replaces a new question with a familiar one.

In this report, I have presented evidence that the largest earthquakes to have struck the midcontinent in historic times did, in fact, trigger sizable events at regional distances. Because at least one these events appears to have had $M_{\mathrm{w}}$ above 5.0, I suggest that triggered earthquakes may represent a nontrivial hazard in central and eastern North America.

\section{Acknowledgments}

I thank Joan Gomberg, Aron Meltzner, Emily Brodsky, Nano Seeber, Hiroo Kanamori, and an anonymous reviewer for reviews and discussions that greatly improved this manuscript; Jerry Hough for advice regarding archival information; and the staff of the Filson Club for their assistance.

\section{References}

Atkinson, G., and D. Boore (1995). Ground-motion relations for eastern North-America, Bull. Seism. Soc. Am. 85, 17-30.

Banks, Daniel (1815). Personal diary, The Filson Club Historical Society, Louisville, Kentucky.

Bendick, R., R. Bilham, E. Fielding, V. Gaur, S. E. Hough, G. Kier, M. N. Kulkarni, S. Martin, K. Mueller, and M. Mukul (2001). The January 26, 2001 Bhuj, India earthquake, Seism. Res. Lett. 72, 328-335.

Bodin, P., and J. Gomberg (1994). Triggered seismicity and deformation between the Landers, California, and Little-Skull-Mountain, Nevada, earthquakes, Bull. Seism. Soc. Am. 84, 835-843.

Brodsky, E. E., B. Sturtevant, and H. Kanamori (1998). Earthquakes, volcanoes, and rectified diffusion, J. Geophys. Res. 103, 23,827-23,838.

Brodsky, E. E., V. Karakostas, and H. Kanamori (2000). Seismicity in Greece triggered by the August, 1999 Izmit, Turkey earthquake, Geophys. Res. Lett. 27, 2741-2744.

Casseday, B. (1852). The History of Louisville from Its Earliest Settlement to 1852, Hyull and Bros., Louisville, Kentucky, pp. 123-124.

Drake, D. (1815). Natural and Statistical View, or Picture of Cincinnati and the Miami County, illustrated by maps, Looker and Wallace, Cincinnati, pp. 235, 241-242.

Frankel, A., C. Mueller, T. Barnhard, D. Perkins, E. V. Leyendecker, N. Dickman, S. Hanson, and M. Hopper (1996). National seismic hazard maps: documentation, U.S. Geol. Surv. Open-File Rept. 96-532, $69 \mathrm{pp}$.

Fuller, M. L. (1912). The New Madrid Earthquakes, U.S. Geol. Surv. Bull. 494.

Gomberg, J. (1996). Strain changes and triggered seismicity following the M(w) 7.3 Landers, California, earthquake, J. Geophys. Res. 101, 751764.

Gomberg, J., and S. Davis (1996). Strain changes and triggered seismicity at The Geysers, California, J. Geophys. Res. 101, 733-749.
Hill, D. P., P. A. Reasenberg, A. Michael, W. J. Arabaz, G. Beroza, D. Brunmbaugh, J. N. Brune, R. Castro, S. Davis, D. DePolo, W. L. Ellsworth, J. Gomberg, S. Harmsen, L. House, S. M. Jackson, M. J. S. Johnston, L. Jones, R. Keller, S. Malone, L. Munguia, S. Nava, J. C. Pechmann, A. Sanford, R. W. Simpson, R. B. Smith, M. Stark, M. Stickney, A. Vidal, S. Walter, V. Wong, and J. Zollweg (1992). Seismicity remotely triggered by the magnitude 7.3 Landers, California, earthquake, Science 260, 1617-1623.

Hough, S. E., J. G. Armbruster, L. Seeber, and J. F. Hough (2000). On the Modified Mercalli Intensities and Magnitudes of the 1811-1812 New Madrid, Central United States earthquakes, J. Geophys. Res. 105, 23,839-23,864.

Hough, S. E., and H. Kanamori (2001). Source properties of earthquakes near the Salton Sea triggered by the 10/16/1999 M7.1 Hector Mine, California earthquake, Bull. Seism. Soc. Am. (in press).

Johnston, A. C. (1996a). Seismic moment assessment of earthquakes in stable continental regions. II. Historical seismicity, Geophys. J. Int. 125, 639-678.

Johnston, A. C. (1996b). Seismic moment assessment of earthquakes in stable continental regions. III. New Madrid 1811-1812, Charleston 1886, and Lisbon 1755, Geophys. J. Int. 126, 314-344.

Johnston, A. C., and E. S. Schweig (1996). The enigma of the New Madrid earthquakes of 1811-1812, Annu. Rev. Earth Planet. Sci. Lett. 24, 339-384.

Mauk, F., D. Christensen, and S. Henry (1982). The Sharpsburg, Kentucky, earthquake 27 July 1980: main shock parameters and isoseismal maps, Bull. Seism. Soc. Am. 72, 221-236.

Mitchill, S. L. (1815). A detailed narrative of the earthquakes which occurred on the 16th day of December, 1811, Trans. Lit. Philos. Soc. N. Y. 1, 281-307.

Nuttli, O. W. (1973). The Mississippi Valley earthquakes of 1811 and 1812 intensities, ground motion, and magnitudes, Bull. Seism. Soc. Am. 63, 227-248.

Seeber, L. (2000). Triggered earthquakes and hazard in stable continental regions, Rep. to U.S. Army Corp. Eng, Waterways Exp. Station, Vicksburg, Mississippi.

Seeber, L., and J. G. Armbruster (1991). The NCEER-91 earthquake catalog: improved intensity-based magnitudes and recurrence relations for U.S. earthquakes east of New Madrid, National Center for Earthquake Engineering Research, NCEER-91-0021.

Street, R. (1982). A contribution to the documentation of the 1811-1812 Mississippi Valley earthquake sequence, Earthquake Notes 53, 39-52.

Street, R. (1984). The historical seismicity of the central United States: 1811-1928, U.S. Geol. Surv. Final Rept., 316 pp.

Townend, J., and M. Zoback (2000) How faulting keeps the crust strong, Geology 28, 399-402.

U.S. Geological Survey

$525 \mathrm{~S}$. Wilson Avenue

Pasadena, California 91106

Manuscript received 12 October 2000. 